\title{
Pembuatan Film Animasi "TEMAN" Menggunakan Teknik Puppet Pin dan Duik sebagai Media Edukasi Anak
}

\author{
Eriya, Fariz Arizky Zhafiri \\ Program Studi Teknik Multimedia dan Jaringan, Jurusan Teknik Informatika \\ Politeknik Negeri Jakarta \\ J1. Prof. Dr. G.A Siwabessy, Kampus UI Depok \\ eriya@tik.pnj.ac.id, fariz arizky@yahoo.com \\ Diterima: 28 Maret 2017. Disetujui: 21 April 2017. Dipublikasikan: Mei 2017
}

\begin{abstract}
Abstrak - Animasi memiliki fungsi sebagai alat penghibur dan pendidik, salah satunya adalah untuk membantu proses memvisualisasikan cerita dalam rangka memberikan edukasi kepada anak-anak. Penyampaian edukasi melalui media animasi akan mudah untuk dipahami anak, salah satunya untuk mengajarkan tentang kebaikan dalam kehidupan seharihari. Film animasi "TEMAN" berupaya untuk membangkitkan rasa toleransi dan menghargai perbedaan yang ada pada kehidupan sehari-hari. Dalam pembuatan film animasi "TEMAN" digunakan teknik Puppet Pin dan Duik untuk menggerakkan karakter dengan gerakan yang sederhana misalnya gerakan berjalan dan berlari. Sedangkan Duik digunakan untuk membuat controller pada wajah karakter yang berfungsi untuk mengubah ekspresi wajah karakter dan juga membantu animator mempermudah pengerjaan Lip Sync karakter. Berdasarkan hasil pengujian dengan menggunakan teknik Puppet Pin dihasilkan gerakan yang halus pada karakter. Penggunaan teknik Duik menghasilkan kesesuaian ekspresi dengan dialog serta gerak mulut dengan baik.
\end{abstract}

Kata Kunci: film animasi, Puppet Pin, Duik, animasi $2 D$.

\section{PENDAHULUAN}

Animasi secara harfiah berarti membawa hidup atau bergerak[1] yang mempunyai arti secara umum menganimasi suatu obyek menjadi benda yang bergerak dan agar obyek tersebut menjadi hidup. Pembuatan film animasi 2D didasari dengan berbagai teknik, seperti teknik frame-by-frame, shape tweening, motion tweening, masking, dan motion guide. Seiring berkembangnya waktu, muncul teknik baru dalam membuat animasi 2D salah satunya yaitu teknik
Puppet Pin dan Duik yang akan dipakai dalam pembuatan film animasi "TEMAN". Menurut [1], pembuatan dengan teknik Puppet Pin terfokus dalam menggerakkan anggota badan pada karakter animasi 2D, intinya yaitu menggerakkan/menganimasikan karakter atau tokoh animasi dengan tool puppet pin tersebut. Puppet pin ini bekerja dengan cara melengkungkan gambar berdasarkan posisi pin yang telah dibuat. Teknik duik digunakan sebagai alat kontrol yang juga memiliki fungsi untuk menggerakkan karakter.

Animasi memiliki fungsi sebagai alat penghibur dan pendidik, salah satunya adalah untuk membantu proses memvisualisasikan cerita dalam rangka memberikan edukasi kepada anak-anak. Penyampaian edukasi melalui media animasi akan mudah untuk dipahami anak, salah satunya untuk mengajarkan tentang kebaikan dalam kehidupan sehari-hari. Untuk itu dibuat sebuah film animasi "TEMAN". Animasi "TEMAN berisikan cerita tentang pentingnya menghargai perbedaan antara sesama manusia, dibuat untuk memberikan edukasi kepada anak-anak agar lebih menghargai perbedaan. Pembuatan film animasi ini menggunakan teknik Puppet Pin dan teknik Duik. Teknik puppet pin digunakan untuk membuat gerakan pada karakter animasi. Dan teknik duik lebih difokuskan penggunaannya pada bagian wajah, lebih tepatnya untuk merubah ekspresi pada karakter.

\section{TINJAUAN PUSTAKA}

A. Animasi

Animasi adalah gambar bergerak berbentuk dari sekumpulan obyek (gambar) yang disusun secara 
beraturan mengikuti alur pergerakan yang telah ditentukan pada setiap pertambahan hitungan waktu yang terjadi [2]. Gambar tersebut dapat berupa gambar makhluk hidup, benda mati, ataupun tulisan. Kata animasi itu sendiri sebenarnya penyesuaian dari kata animation yang berasal dari kata dasar to animate dalam kamus umum Inggris - Indonesia berarti menghidupkan [3].

Animasi merupakan proses membuat obyek yang asalnya obyek mati, kemudian disusun dalam posisi yang berbeda seolah menjadi hidup. Di dalam animasi ada dua obyek penting, yaitu obyek atau gambar dan alur gerak. Animasi secara umum dapat dikatakan sebagai suatu sequence gambar yang ditampilkan pada tenggang waktu (timeline) tertentu sehingga tercipta sebuah ilusi gambar bergerak.

\section{B. Puppet Pin}

Tool Puppet pin berfungsi untuk memberikan pergerakan natural pada gambar dengan cepat, termasuk still image, shapes, dan text [4]. Efek puppet bekerja berdasarkan posisi pin yang ditempatkan atau digerakkan. Pin-pin tersebut menggambarkan bagian obyek mana yang harus digerakkan, diam, dan berada di depan [5]. Berikut adalah beberapa jenis-jenis puppet seperti terlihat pada Gambar 1 .

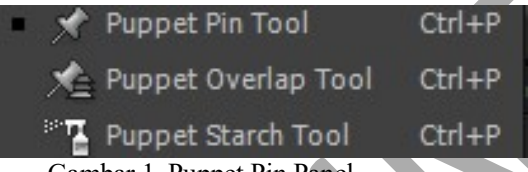

a. Puppet Pin Tool

Berfungsi untuk menempatkan dan menggerakkan pin.

b. Puppet Overlap Tool

Berfungsi untuk menempatkan pin Overlap yang menunjukkan bagian mana dari gambar yang berada di depan ketika perubahan menyebabkan bagian lain bertumpuk

c. Puupet Stratch Tool

Berfungsi untuk menempatkan pin Stratcj dimana akan membuat bagian yang diam akan mengalami sedikit perubahan.

\section{Duik}

Duik adalah tools animasi dan rigging komprehensif untuk Adobe After Effects. Duik menyediakan tools rigging seperti pada software 3D contohnya IK, Controller dan rigging. Biasanya tools tersebut digunakan untuk animasi 3D namun pada software Adobe Affter Effect dapat digunakan pada obyek 2D melalui teknik Duik ini. Dengan Teknik
Duik maka karakter yang kompleks dapat diberi tulang dan lebih mudah dianimasikan [6]. Duik mempunyai empat tool box yaitu rigging, automation, animation dan kamera yang dapat dilihat pada gambar di atas ikon sebelah kanan atas, beserta dengan pengaturan panel dan help panel seperti pada Gambar 2 .

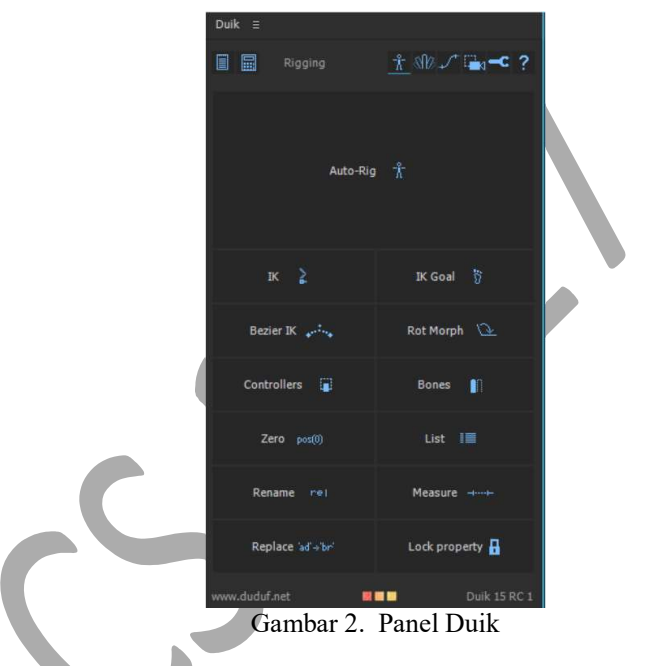

D. 12 Prinsip Animasi

Dalam pembuatan film animasi "TEMAN" 12 prinsip animasi menjadi acuan animator dalam menganimasikan karakter maupun obyek yang lainnya, berikut adalah 12 prinsip animasi tersebut [7].

- Pose to Pose

- Timing

- Secondary Action

- Ease in/out

- Anticipation

- Follow Trough and Overlapping Action

- Arc

- Exaggeration

- Squash and Stretch

- Stagging

- Appeal

- Personality

\section{PERANCANGAN DAN REALISASI}

A. Deskripsi Karakter

Animasi ini menggunakan lima karakter yang terdapat pada Gambar 3 sampai 7, yaitu :

1. Rendi: karakter ini memiliki sifat yang tertutup, penyendiri, tidak mudah bergaul dengan orang lain. Karakter ini merupakan karakter yang introvert sehingga dia menciptakan TEMAN khayalan sendiri yang bernama Bombom. 


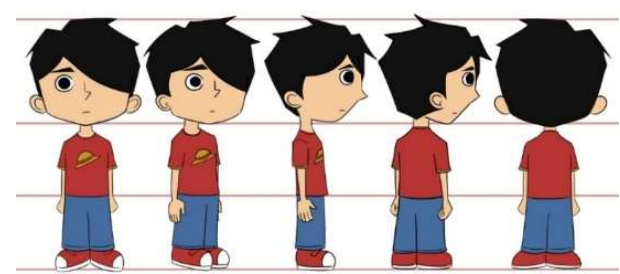

Gambar 3. Karakter Rendi

2. Ipang: karakter ini memiliki sifat jahil, leadership, pemarah. Karakter ini merupakan pemimpin karakter antagonis yang lainnya, suka menjahili anak satu kelasnya.

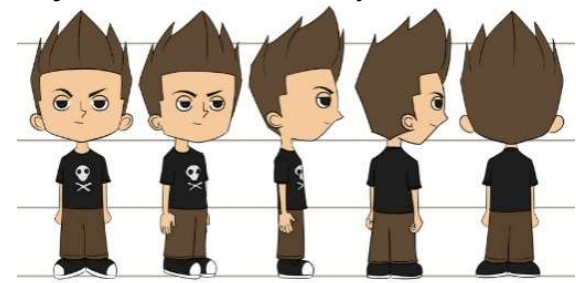

Gambar 4. Karakter Ipang

3. Revi: karakter ini mempunyai sifat cuek, pendiam, jutek dan usil. Revi merupakan salah satu sahabat ipang yang juga suka mengusili TEMAN kelasnya.

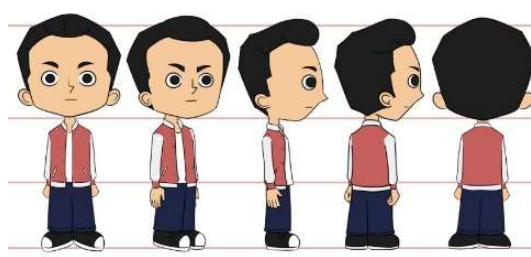

Gambar 5. Karakter Revi

4. Abay: karakter ini mempunyai sifat periang, aneh dan jahil. Karakter ini juga merupakan sahabat dari Ipang dan Revi.

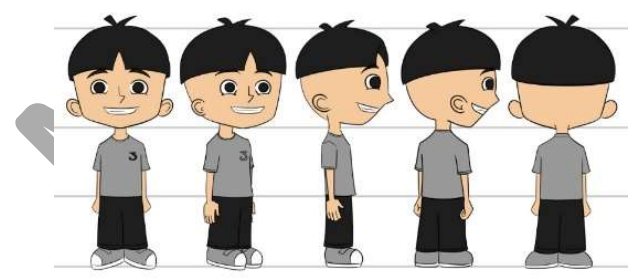

Gambar 6. Karakter Abay

5. Bombom: karakter ini mempunyai sifat bijaksana, baik. Bombom merupakan TEMAN khayalan yang diciptakan berdasarkan sifat introvert Rendi.

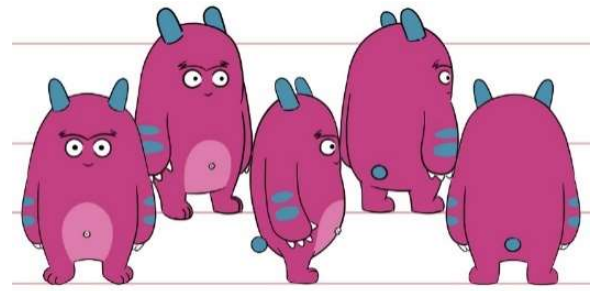

Gambar 7. Karakter Bombom

\section{B. Animasi Karakter dengan Puppet Pin}

Teknik Puppet pin digunakan untuk menganimasikan pergerakan karakter dengan menggunakan perangkat lunak Adobe After Effect CS6. Ada beberapa jenis gerakan yang digunakan pada animasi "TEMAN" diantara lain yaitu run cycle, walk cycle, dan gerakan-gerakan sederhana yang lainnya. Salah satu contohnya yang dipakai adalah run cycle atau animasi dengan gerakan berlari.

\section{a. Penempatan Pin Puppet Pada Karakter}

Pada tahap ini, pin puppet diletakkan pada bagian sendi dan juga pada bagian-bagian yang ingin digerakkan misalnya pada bahu, siku, pergelangan tangan, leher, lutut dan bagian-bagian yang lainnya. Sehingga gambar karakter harus dipisah menjadi beberapa bagian, misalnya badan, kepala, tangan dan kaki agar dapat menggunakan teknik puppet pin ini seperti pada Gambar 8. Untuk mempermudah pada tahapan penggerakan karakter penulis menggunakan tools null object pada Gambar 9 dan diletakkan pada bagian yang akan diberi pin puppet.

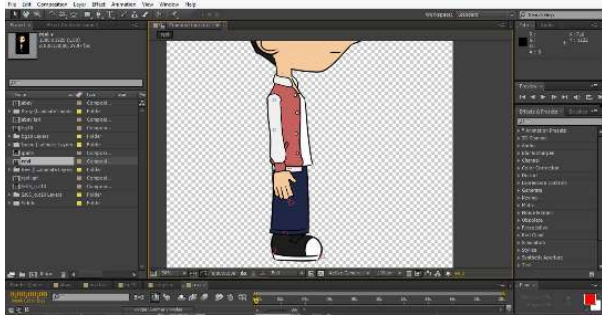

Gambar 8. Penempatan pin Puppet pada karakter

Setelah null object dipasang pada bagian yang sudah ditentukan, tahapan selanjutnya adalah memberikan pin pada masing-masing bagian gambar dengan posisi null object yang sudah ada. 


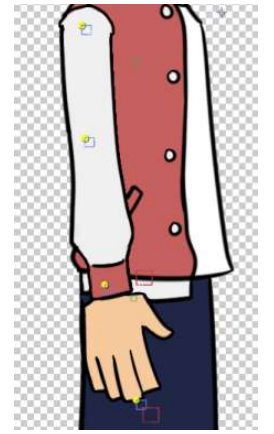

Gambar 9. Penempatan Null Object

b. Pemasangan Pin Puppet

Setelah pin puppet dipasang pada gambar karakter, langkah selanjutnya adalah membuat gambar menyatu dengan pin puppet dengan menggunakan script seperti Gambar 10. Script tersebut berfungsi untuk melekatkan pin puppet (pada gambar karakter) dengan null object, sehingga jika null object digerakkan maka gambar karakter juga akan ikut bergerak.

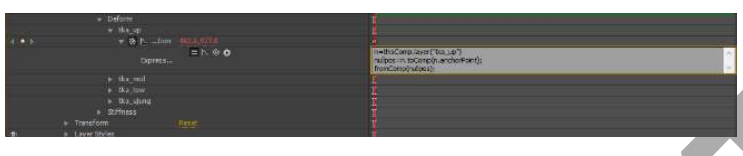

Gambar 10. Script Pin Puppet

\section{c. Parenting}

Setelah pin puppet dilekatkan pada gambar karakter, langkah selanjutnya adalah menghubungkan antara Pin Puppet yang satu dengan yang lainnya, yaitu dengan cara parenting pada layer null object yang ada di Gambar 11.

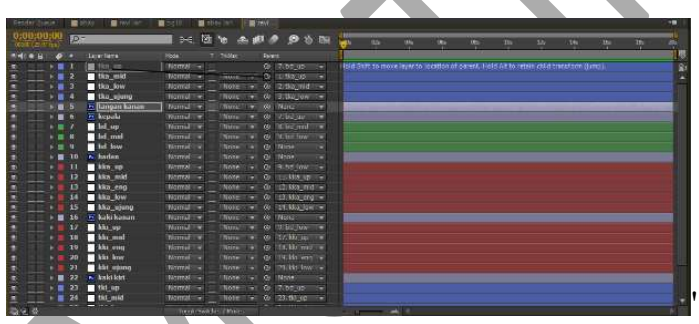

Gambar 11. Parenting Puppet

Layer null object pada ujung jari tangan kanan akan dihubungkan dengan layer null object pada bagian pergelangan tangan kanan. Sedangkan layer null object pada bagian pergelangan tangan kanan akan dihubungkan dengan layer null object pada bagian siku tangan kanan, begitu juga pada semua bagian-bagian yang lainnya.

\section{d. Puppet Stretch Tool}

Setelah semua pin puppet terhubung dengan pin puppet yang lain, langkah selanjutnya adalah memberikan Puppet Stretch Tool seperti Gambar 12 yang berfungsi untuk memberikan efek tulang pada gambar sehingga gambar tidak terlalu lentur dan kaku ketika digerakkan. Untuk mengatur kelenturan tulang pada gambar karakter dengan cara mengubah nilai Amount yang berfungsi mengatur presentase kelenturan, dan nilai Extent untuk untuk luas area yang dipengaruhi oleh efek puppet stretch tool.

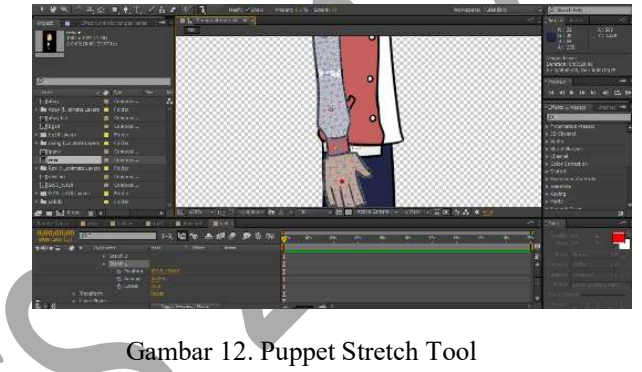

Animating

Setelah gambar diberi efek puppet stretch tool, langkah selanjutnya adalah menggerakkan karakter. Penulis mengambil salah satu gerakan yaitu gerakan berlari pada karakter revi. Ada beberapa tahapan dalam menggerakkan karakter. Key Position digunakan sebagai inti dari gerakan karakter. Pada tahap ini null object akan digerakkan sehingga karakter berpose lari

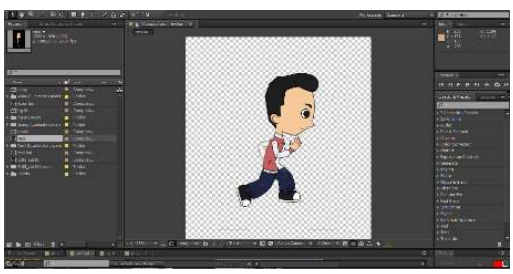

Gambar 13. Key Position

Untuk membuat karakter bergerak yaitu dengan cara menggunakan toogle keyframe pada timeline frame pertama dan pada frame selanjutnya dan pose karakter diubah menjadi key position yang lain seperti pada Gambar 13 dan 14. Setelah key position dibuat, langkah selanjutnya adalah memberikan gerakan perantara untuk menghasilkan gerakan animasi yang lebih halus dan juga memberikan secondary action pada karakter. Dengan menggunakan Teknik Puppet Pin diatas dapat mempermudah penganimasian karakter, mempercepat pengerjaan animasi pada karakter dan gerakan yang dihasilkan lebih halus dan natural. 


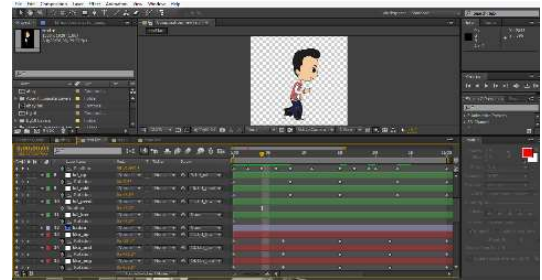

Gambar 14. Key Position 2

\section{Animasi Wajah Karakter dengan Duik}

a. Penempatan Plot Kontroller

Pada tahap ini akan dibuat plot-plot kontroler untuk bagian wajah dengan mengkombinasikan duik dengan null object pada Adobe After Effect CS6. Seperti yang sudah dibahas sebelumnya obyek yang akan dikontrol dengan menggunakan duik adalah mata (bola mata dan kelopak mata), alis dan mulut. Hal ini terlihat pada Gambar 15

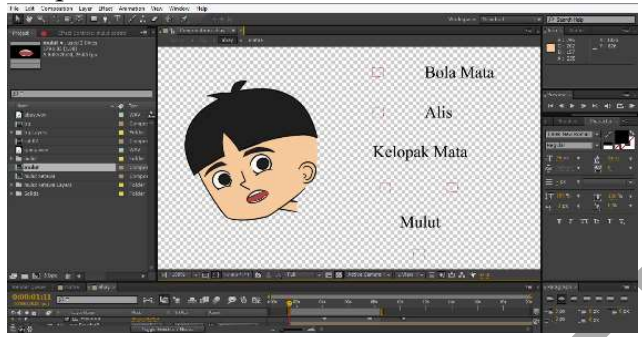

Gambar 15. Pembuatan Plot Controller

b. Menghubungkan Plot Kontroler dengan Obyek

Setelah plot kontroler selesai dibuat, langkah selanjutnya adalah menghubungkan null object dengan obyek-obyek pada wajah karakter. Import Duik dengan cara mengklik File - run script - run script file, open script duik versi 14.11 sehingga akan muncul tampilan duik controller seperti Gambar 16.

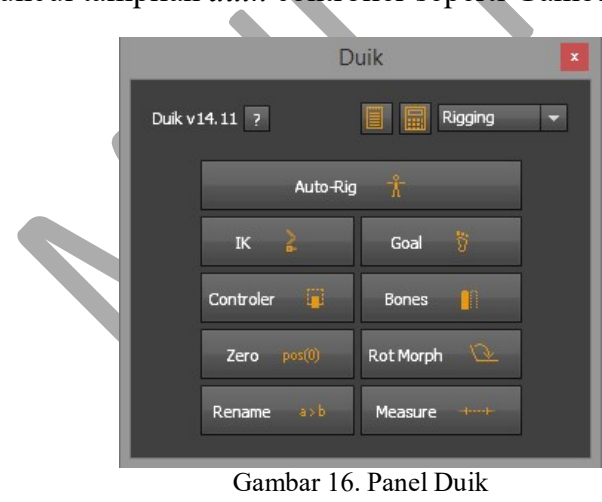

Setelah muncul tampilan seperti Gambar 16, langkah selanjutnya yaitu membuat posisi default obyek wajah karakter (bola mata) dan null object (mata controller) menjadi 0 dengan menggunakan duik controller seperti terlihat pada Gambar 17.

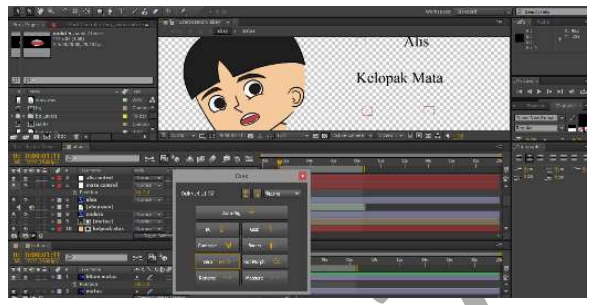

Gambar 17. Penggunakan Duik Pada Null Object

Setelah posisi obyek mata dan null object controller mata menjadi 0 , langkah selanjutnya adalah menghubungkan bola mata dengan null object mata controller. Hal tersebut dapat dilihat pada Gamar 18. Setelah obyek mata dengan null object controller mata terhubung langkah selanjutnya menambahkan script pada Gambar 19 agar bola mata lebih mudah dikontrol.

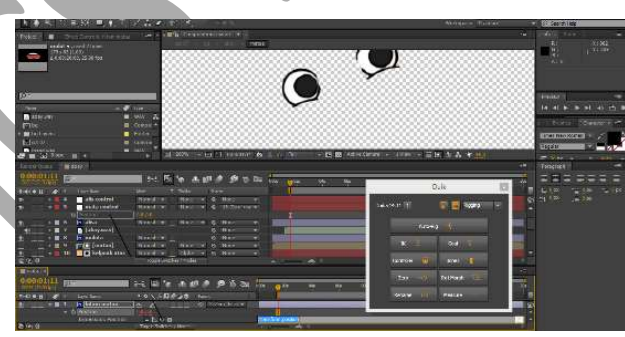

Gambar 18. Parenting Mata

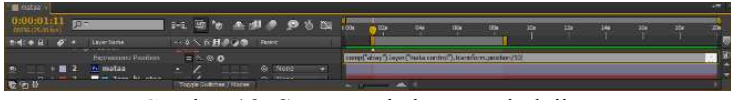

Gambar 19. Script tambahan untuk duik

c. Membuat Kontroler Mulut

Obyek mulut menggunakan teknik duik yang sedikit berbeda dengan yang sebelumnya, dikarenakan mulut mempunyai obyek lebih dari satu, misalnya obyek mulut a, i, u, e, o, mulut diam, mulut tertawa dan masih banyak obyek mulut yang lainnya. Langkah pertama adalah membuat composition baru untuk mulut dengan frame rate sebanyak 25/s dan memasukkan obyek-obyek mulut, terlihat pada Gambar 21.

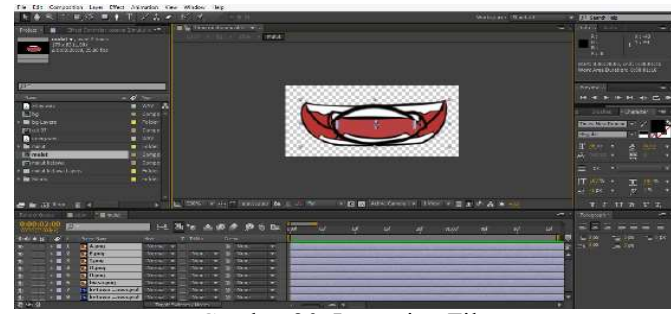

Gambar 20. Importing File 
Setelah obyek mulut dimasukkan pada composition baru, langkah selanjutnya adalah memotong durasi masing-masing obyek menjadi 3 frame untuk mempermudah saat penganimasian pada dubbing karakter seperti terlihat pada Gambar 21.

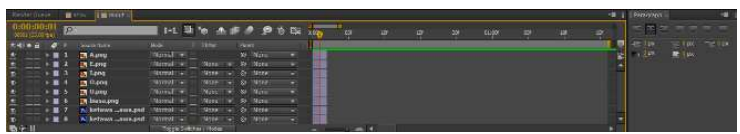

Gambar 21. Pemotongan Durasi

Langkah selanjutnya adalah menyusun layer obyek dengan menggunakan keyframe assistance untuk mempermudah pada tahapan Lip Sync karakter sehingga tampilan akan seperti Gambar 22.

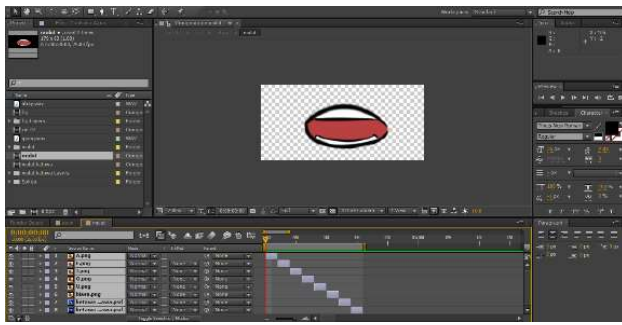

Gambar 22. Penyusunan Layer

Setelah obyek-obyek mulut disusun, langkah selanjutnya ada menghubungkan composition mulut dengan null object mulut controller pada Gambar 23. Cara yang dilakukan untuk menghubungkan composition mulu dengan null object mulut controller sama dengan tahapan yang sebelumnya namun perbedaannya composition mulut menggunakan editable time remapping dan hanya dihubungkan pada koordinat sumbu x pada null object mulut controller.

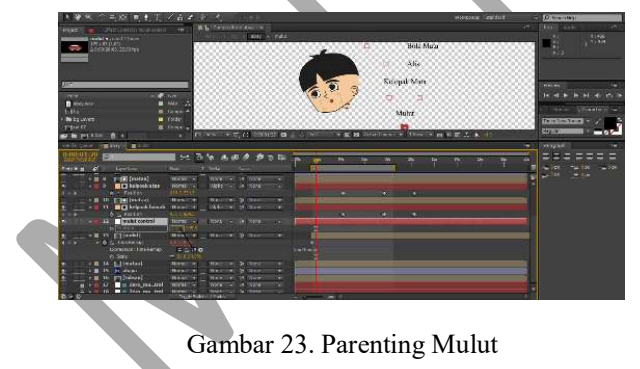

d. Animating \& Lip Sync Karakter

Setelah semua bagian wajah dapat dikontrol dengan benar, tahapan selanjutnya adalah menganimasikan serta lip sync karakter dengan dubbing karakter sebagai acuannya yang dapat dilihat dari Gambar 24 sampai 26.

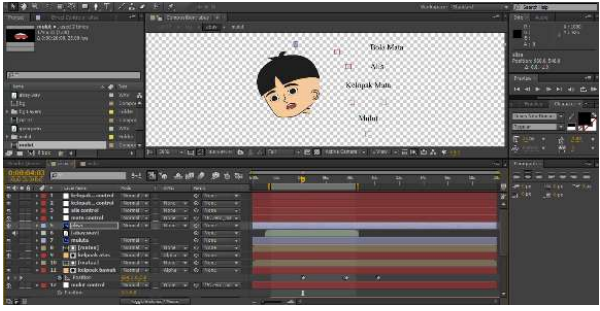

Gambar 24. Importing File Audio

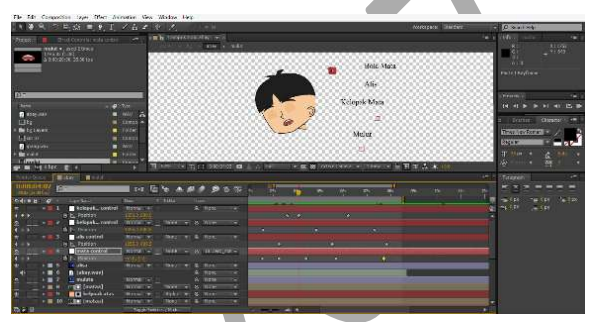

Gambar 25. Animating Wajah

Khusus untuk mulut hanya berpengaruh pada sumbu $\mathrm{x}$ dan untuk membuat mulut tidak selalu berganti saat lipsing penulis menggunakan Toogle Hold Keyframe.

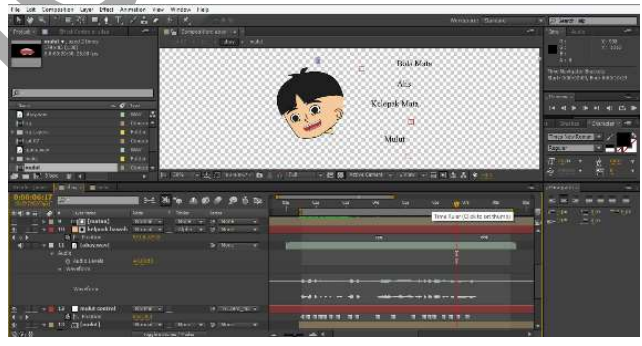

Gambar 26. Lip Sync Karakter

Dengan menggunakan teknik Duik penganimasian wajah pada baik itu mengubah ekspresi wajah karakter, membuat mata berkedip dan juga menyesuaikan gerakan mulut dengan suara karakter menjadi lebih mudah dan cepat karena bagian-bagian pada wajah karakter dikendalikan oleh sebuah kontroler yang mudah untuk dipakai.

\section{Composite}

Pada tahap sebelumnya dengan menggunakan teknik Puppet dan Duik penganimasian suatu karakter masih terpisah dengan dengan karakter, background maupun obyek-obyek yang lain. Untuk menggabungkan karakter dengan obyek dan background dilakukan dengan cara membuat suatu composite pada Gambar 27 lalu menggabungkan karakter background dan obyek tersebut menjadi kesatuan yang utuh sehingga animasi dapat disajikan baik. Beberapa transformasi yang digunakan diantara 
lain adalah opacity, scale, rotation dan position seperti terlihat pada Gambar 28 sampai dengan 32.

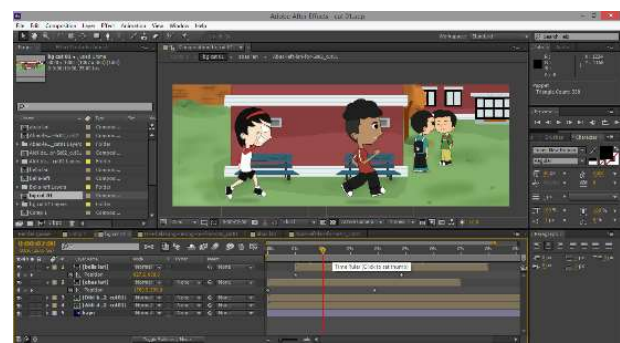

Gambar 27. Compositing Karakter dan Background

\section{a. Opacity}

Pada animasi "TEMAN" opacity digunakan pada saat karakter Bombom muncul. Untuk membuat Bombom muncul opacity dibuat menjadi transparan atau $0 \%$ pada keyframe awal, lalu pada keyframe selanjutnya opacity dibuat menjadi $100 \%$.

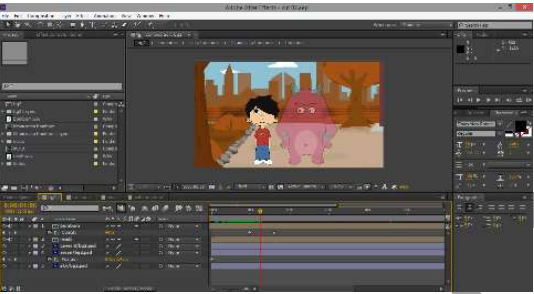

Gambar 28. Opacity Bombom 1

b. Scale

Scale digunakan untuk menganimasikan obyek benda, karakter, dan background. Scale berfungsi membuat obyek menjadi mendekat maupun menjauh agar animasi menjadi lebih natural. Scale dianimasikan dengan menggunakan toogle keyframe, pada keyframe awal obyek mempunyai posisi default atau normal pada keyframe selanjutnya obyek dibuat menjadi lebih besar atau lebih kecil.

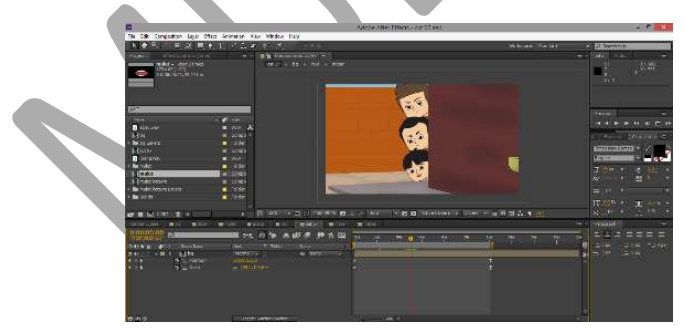

Gambar 29. Transformasi Scale 1

\section{c. Position}

Pada Animasi "TEMAN" Compositing Position digunakan hampir pada setiap adegan, misalnya menggerakkan karakter yang sedang berjalan atau berlari, membuat benda menjadi bergerak dan untuk menggerakkan obyek-obyek yang lainnya.

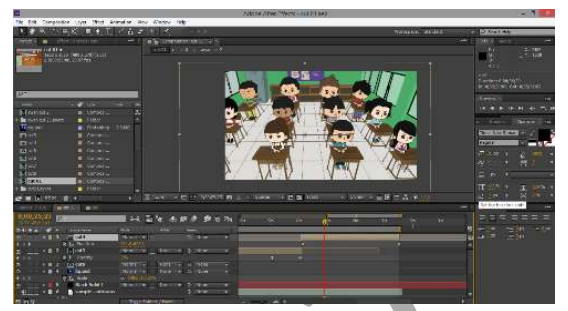

Gambar 30. Transformasi Position

\section{d. Rotation}

Rotation digunakan untuk memutar benda untuk mendukung pergerakan yang ada dianimasi "TEMAN". Untuk menggunakan fungsi rotasi cara yang dilakukan sama dengan langkah sebelumnya yaitu dengan menggunakan toogle pada keyframe awal lalu mengubah rotasi benda pada keyframe selanjutnya.

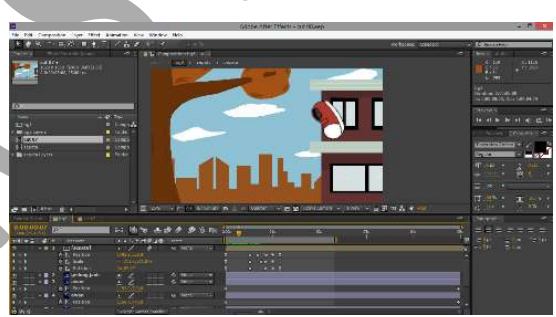

Gambar 31. Transformasi Rotasi

Setelah obyek, karakter dan background melalui proses compose, tahap selanjutnya adalah mengekspor hasil animasi menjadi format H.264 atau mp4 untuk kembali lagi melalui proses editing video dan audio.

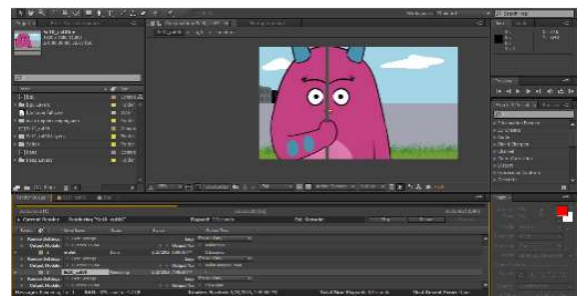

Gambar 32. Proses Rendering

\section{PEMBAHASAN}

a. Deskripsi Pengujian

Pengujian dilakukan dengan cara memperlihatkan film kepada responden lalu memberikan dan menyebarkan kuesionernya secara langsung. 
Kuesioner dibagi menjadi dua macam yaitu kuesioner yang berisi pertanyaan teknis dan kuesioner yang berisi pertanyaan non teknis. Kuesioner non teknis diperuntukkan bagi masyarakat umum, sedangkan kuesioner teknis diperuntukkan bagi seseorang yang mengerti dalam hal animasi. Pengujian ini bertujuan untuk meninjau film dan teknis yang dilakukan pada pembuatan film ini memberikan hasil atau dampak yang baik.

b. Hasil Data Pengujian

Pengujian ditujukan untuk usia 15 - 25 tahun yang terlihat di Tabel 1.

TABEL 1 DISTRIBUSI RESPONDEN BERDASARKAN USIA

\begin{tabular}{|c|c|}
\hline Usia & n \\
\hline $15-20$ tahun & 20 \\
\hline $21-25$ tahun & 20 \\
\hline Total & $\mathbf{4 0}$ \\
\hline
\end{tabular}

- Pernyataan: "Kesesuaian penempatan karakter dalam frame"

Dari hasil perhitungan persentase data, didapatkan hasil $32,5 \%$ responden sangat sesuai, $62,5 \%$ sesuai, $5 \%$ cukup, $0 \%$ pada jawaban kurang dan sangat kurang. Hasil terbesar adalah jawaban baik dengan persentase $62,5 \%$, hal ini membuktikan bahwa penempatan karakter pada frame di film animasi "TEMAN" sudah sesuai.

- Pernyataan: "kesesuaian gerak antisipasi pada karakter"

Dari hasil perhitungan persentase data, didapatkan hasil 5\% responden sangat sesuai, 72,5\% sesuai, $22.5 \%$ cukup, $0 \%$ pada jawaban kurang dan sangat kurang. Hasil terbesar adalah jawaban baik dengan persentase $72,5 \%$. Hal ini membuktikan bahwa kesesuaian gerak antisipasi pada karakter pada film animasi“TEMAN" sudah sesuai.

- Pernyataan: "Kesesuaian ekspresi dengan dialog" Dari hasil perhitungan persentase data, didapatkan hasil $15 \%$ responden sangat sesuai, $60 \%$ sesuai, $25 \%$ cukup, $0 \%$ pada jawaban kurang dan sangat kurang. Hasil terbesar adalah jawaban baik dengan persentase $60 \%$, hal ini membuktikan bahwa Kesesuaian ekspresi dengan dialog pada film animasi "TEMAN" sudah baik, sehingga dapat disimpulkan bahwa penggunaan teknik Duik dalam hal animasi ekspresi wajah karakter adalah sesuai.

- Pernyataan: "kesesuaian gerak mulut dengan dubbing karakter"

Dari hasil perhitungan persentase data, didapatkan hasil $20 \%$ responden sangat sesuai, $62,5 \%$ sesuai, 7,5\% cukup, 2,5\% pada jawaban kurang dan $0 \%$ untuk jawaban sangat kurang. Hasil terbesar adalah jawaban baik dengan persentase $62,5 \%$, hal ini membuktikan bahwa kesesuaian gerak mulut dengan dubbing karakter pada film animasi "TEMAN" sudah baik, hal ini membuktikan teknik duik mempermudah pengerjaan Lip Sync karakter dengan dubbing dan juga menghasilkan gerakan mulut yang sesuai.

- Pernyataan: "kehalusan gerakan karakter"

Dari hasil perhitungan persentase data, didapatkan hasil $20 \%$ responden sangat sesuai, $50 \%$ sesuai, $25 \%$ cukup, $5 \%$ pada jawaban kurang dan $0 \%$ untuk jawaban sangat kurang. Hasil terbesar adalah jawaban baik dengan persentase $50 \%$, hal ini membuktikan bahwa kehalusan gerakan karakter pada film animasi "TEMAN" sudah sesuai, hal ini membuktikan bahwa dengan menggunakan teknik Puppet Pin gerakan animasi menjadi lebih halus.

\section{PENUTUP}

A. Kesimpulan

Berdasarkan hasil yang telah dikerjakan yaitu penggunaan teknik Puppet Pin dan Duik pada film animasi "TEMAN", maka dapat diambil beberapa kesimpulan, yaitu :

1. Penggunaan teknik animasi Puppet Pin pada Adobe After Effect dapat mempermudah dan mempercepat penganimasian karakter dibandingkan dengan teknik yang lain contohnya frame by frame, namun penggunaan teknik Puppet pin hanya bisa digunakan pada gerakan-gerakan yang sederhana. Gerakan yang dihasilkan oleh teknik Puppet Pin lebih halus dan natural, dengan catatan digunakan untuk menganimasikan gerakangerakan yang sederhana misalnya gerakan berjalan, berlari, jatuh dan gerakan sederhana lainnya.

2. Bagian-bagian wajah seperti mulut, alis, mata dapat dikendalikan oleh kontroler yang dibuat dengan menggunakan teknik Duik, hanya dengan menggeser koordinat kontroler yang sudah dihubungkan dengan wajah karakter, maka secara otomatis bagian-bagian wajah akan ikut berubah koordinatnya, sehingga penganimasian ekspresi wajah pada karakter menjadi lebih mudah.

3. Berdasarkan pengujian teknis didapatkan hasil $20 \%$ responden sangat sesuai, 50\% sesuai, 25\% cukup, 5\% pada jawaban kurang bahwa gerakan yang dihasilkan oleh karakter sudah halus. Lalu pada pengujian kesesuaian gerakan mulut dengan dubbing karakter didapatkan hasil 20\% responden menyatakan sangat sesuai, $62,5 \%$ sesuai, 7,5\% cukup, 2,5\% kurang baik. Sedangkan 15\% responden menyatakan sangat baik, 60\% sesuai, 
$25 \%$ cukup pada pengujian kesesuaian ekspresi wajah karakter dengan dialog.

\section{B. Saran}

Dari pelaksanaan dan pengerjaan penelitian yang dilakukan, animasi "TEMAN" memiliki saran sebagai berikut:

Gerakan yang dihasilkan pada karakter sudah halus namun perlu untuk diperhalus lagi terutama pada sendi-sendi yang ada pada karakter dan ekspresi wajah pada karakter dibuat lebih baik lagi sehingga karakter lebih menjiwai peran dan dialognya.

\section{REFERENSI}

[1] A. Nugroho, Mawan. 2010, Maret. 12 Prinsip Animasi

[2] Amin. 2014. "Penjelasan fungsi Tools Panel di After Effet"

[3] Dufresne, Nicholas 2015. "Rigging DUIK Animation"

[4] Madcoms. 2013. Kupas Tuntas Adobe After Effect CS6. Yogyakarta : Andi Offset.

[5] Meliana Luwuk, Liliana, Djoni H. Setiabudi. 2012. "Aplikasi Penggabungan Obje Transparan Kedalam Sebuah Image". Jurnal Saintikom, Vol.1-No.1, Agustus 2012

[6] Muhammad, Nur. 2010. "Pengenalan Dasar After Effect".

[7] Priatmono, Dody. 2013. Jenis-Jenis Animasi. 